\begin{tabular}{|c|c|c|c|}
\hline \multicolumn{4}{|c|}{ Table } \\
\hline & & $\begin{array}{l}\text { LEN+pembro } \\
(n=65)\end{array}$ & $\begin{array}{c}\text { TPC } \\
(n=65)\end{array}$ \\
\hline & Median PFS, months (95\% Cl) & $10.7(5.6, N R)$ & $3.7(3.1,4.4)$ \\
\hline & $\begin{array}{l}\text { PFS HR }(95 \% \mathrm{Cl}) \\
P \text {-value }\end{array}$ & \multicolumn{2}{|c|}{$\begin{array}{c}0.36(0.23,0.57) \\
<0.0001\end{array}$} \\
\hline & Median OS, months ( $95 \%$ CI) & NR (NR) & $8.6(5.5,12.9)$ \\
\hline & $\begin{array}{l}\text { OS HR vs TPC }(95 \% \mathrm{Cl}) \\
P \text {-value }\end{array}$ & \multicolumn{2}{|c|}{$\begin{array}{c}0.37(0.22,0.62) \\
<0.0001\end{array}$} \\
\hline & ORR, \% (95\% Cl) & $40.0(28.0,52.9)$ & $12.3(5.5,22.8)$ \\
\hline & $\begin{array}{l}\text { Difference, \% }(95 \% \mathrm{CI}) \\
P \text {-value }\end{array}$ & \multicolumn{2}{|c|}{$\begin{array}{c}27.7(12.9,41.7) \\
0.0002\end{array}$} \\
\hline & Disease control rate, $\%(95 \% \mathrm{Cl})$ & $73.8(61.5,84.0)$ & $47.7(35.1,60.5)$ \\
\hline & $\begin{array}{l}\text { Median duration of response }{ }^{\circ}, \\
\text { months (range) }\end{array}$ & $\begin{array}{c}\text { NR } \\
\left(2.1^{+}, 20.4^{+}\right)\end{array}$ & $\begin{array}{c}4.1 \\
\left(1.9^{+}, 15.6^{+}\right)\end{array}$ \\
\hline & $\begin{array}{l}\text { Median time to response }{ }^{2} \text {, } \\
\text { months (range) }\end{array}$ & $2.9(1.7,16.3)$ & $1.9(1.8,3.7)$ \\
\hline
\end{tabular}

the TPC group (data cutoff: October 26, 2020). PFS (median 10.7 vs 3.7 months) and OS (median not reached vs 8.6 months) were longer with LEN+pembro vs TPC. ORR was greater with LEN+pembro (40.0\%) vs TPC (12.3\%). Additional results are in the Table. Grade $\geq 3$ treatment-emergent adverse events occurred in $95 \%$ and $73 \%$ of patients in the LEN+pembro and TPC groups, respectively.

Conclusions LEN+pembro improved PFS, OS, and ORR vs TPC in patients with $\mathrm{dMMR}$ aEC, with a manageable safety profile generally consistent with all-comers and previous studies.

\section{3/\#149 ANTITUMOR ACTIVITY OF DOSTARLIMAB IN PATIENTS WITH ADVANCED OR RECURRENT MISMATCH REPAIR-DEFICIENT OR PROFICIENT- CANCER BY PRIOR THERAPY: RESULTS FROM THE GARNET STUDY}

${ }^{1} \mathrm{~A}$ Oaknin*, ${ }^{2} \mathrm{~L}$ Gilbert, ${ }^{3} \mathrm{~A}$ Tinker, ${ }^{4} \mathrm{~J}$ Brown, ${ }^{5} \mathrm{C}$ Mathews, ${ }^{6} \mathrm{~J}$ Press, ${ }^{7} \mathrm{R}$ Sabatier, ${ }^{8} \mathrm{D}$ O'Malley, ${ }^{9} \mathrm{~V}$ Samouëlian, ${ }^{10} \mathrm{~V}$ Boni, ${ }^{11} \mathrm{~L}$ Duska, ${ }^{12} \mathrm{~S}$ Ghamande, ${ }^{13} \mathrm{P}$ Ghatage, ${ }^{14} \mathrm{R}$ Kristeleit, ${ }^{15} \mathrm{C}$ Leath lii, ${ }^{16} \mathrm{~J}$ Veneris, ${ }^{17} \mathrm{~T}$ Duan, ${ }^{18} \mathrm{E} \mathrm{Im},{ }^{19} \mathrm{~B}$ Pothuri. ${ }^{1}$ Vall $\mathrm{d}^{\prime}$ Hebron University Hospital, Vall d'Hebron Institute of Oncology (VHIO), Department of Medical Oncology, Barcelona, Spain; ${ }^{2}$ McGill University Health Centre-Rl, Gynecologic Oncology Division, Montreal, Canada; ${ }^{3} B C$ Cancer, Department of Medical Oncology/department of Medicine, Vancouver, Canada; ${ }^{4}$ Levine Cancer Institute, Atrium Health, Division of Gynecologic Oncology, Charlotte, USA; ${ }^{5}$ Women and Infants Hospital of Rhode Island, Gynecologic Oncology, Providence, USA; ${ }^{6}$ Swedish Cancer Institute Gynecologic Oncology and Pelvic Surgery, Gynecologic Oncology and Pelvic Surgery, Seattle, USA; ${ }^{7}$ Institut Paoli Calmettes, Aix-Marseille University, Department of Medical Oncology, Marseille, France; ${ }^{8}$ The Ohio State University - James CCC, Department of Obstetrics and Gynecology, Columbus, USA; ${ }^{9}$ Gynecologic Oncology Service, CHUM, Université de Montréal, Department of Obstetrics and Gynecology, Montreal, Canada; ${ }^{10}$ START Madrid-CIOCC, Centro Integral Oncológico Clara Campal, Hospital Universitario HM Sanchinarro, Early Drug Development Unit, Medical Oncology, Madrid, Spain; ${ }^{11}$ Emily Couric Clinical Cancer Center, University of Virginia, Department of Obstetrics and Gynecology, Charlottesville, USA; ${ }^{12}$ Georgia Cancer Center, Augusta University, Gynecologic Oncology, Augusta, USA; ${ }^{13}$ University of Calgary, Department of Gynecological Oncology, Calgary, Canada; ${ }^{14}$ Guy's and St Thomas' Hospital NHS Foundation Trust, Medical Oncology, London, UK; ${ }^{15} \mathrm{O}^{\prime} \mathrm{Neal}$ Comprehensive Cancer Center, University of Alabama at Birmingham, Division of Gynecologic Oncology, Birmingham, USA; ${ }^{16}$ GlaxoSmithKline, Oncology Clinical Department, Waltham, USA; ${ }^{17}$ GlaxoSmithKline, Oncology Clinical Statistics, Waltham, USA; ${ }^{18}$ GlaxoSmithKline, Clinical Development, Waltham, USA; ${ }^{19}$ New York University, NYU Langone Health, Perlmutter Cancer Center, Department of Obstetrics and Gynecology, New York, USA

\subsection{6/ijgc-2021-IGCS.3}

Objectives Dostarlimab is a humanized programmed death 1 (PD-1) receptor monoclonal antibody that blocks interactions
Abstract 0003/\#149 Table 1

\begin{tabular}{|l|c|c|c|c|}
\hline \multirow{2}{*}{ Variable } & \multicolumn{3}{|c|}{ dMMR/MSI-H EC } & \multicolumn{2}{c|}{ MMRp EC } \\
\cline { 2 - 6 } & $\mathrm{N}$ & $\mathrm{n}(\% ; 95 \% \mathrm{Cl})$ & $\mathrm{N}$ & $\mathrm{n}(\% ; 95 \% \mathrm{Cl})$ \\
\hline ORR by RECIST v1.1 & 108 & $47(43.5 ; 34.0-53.4)$ & 142 & $19(13.4 ; 8.3-20.1)$ \\
\hline Prior anticancer therapy & & & & \\
1 prior LOT & 69 & $33(47.8 ; 35.6-60.2)$ & 65 & $9(13.8 ; 6.5-24.7)$ \\
$\geq 2$ prior LOTs & 39 & $14(35.9 ; 21.252 .8)$ & 77 & $10(13.0 ; 6.4-22.6)$ \\
\hline
\end{tabular}

with PD-1 ligands. GARNET is a phase 1 study assessing antitumor activity and safety of dostarlimab monotherapy in patients with advanced solid tumors.

Methods This multicenter, open-label, single-arm study is conducted in 2 parts: dose escalation and expansion. Patients with advanced or recurrent mismatch repair-deficient (dMMR) or microsatellite instability-high (MSI-H) endometrial cancer (EC) or mismatch repair-proficient (MMRp) EC that progressed on or after a platinum regimen received dostarlimab $500 \mathrm{mg}$ intravenously Q3W for 4 cycles, then $1000 \mathrm{mg}$ Q6W until disease progression or discontinuation. Primary endpoints were objective response rate (ORR) and duration of response by BICR using RECIST v1.1. Here we report ORR in dMMR/ MSI-H and MMRp EC by prior lines of therapy (LOTs).

Results Efficacy analyses included 108 dMMR/MSI-H and 142 MMRp patients. ORR was $43.5 \%$ in dMMR/MSI-H and $13.4 \%$ in MMRp. ORR was slightly higher (47.8\%) in patients with dMMR/MSI-H with 1 prior LOT but lower $(35.9 \%)$ in those who received $\geq 2$ prior LOTs. In the MMRp population, ORR was similar, regardless of prior LOTs. Safety has been previously reported. ${ }^{1}$

Conclusions Dostarlimab demonstrated antitumor activity in recurrent or advanced dMMR/MSI-H and MMRp EC regardless of number of prior LOTs. Patients with dMMR/MSI-H EC who received 1 prior LOT had slightly higher ORR than those who received $\geq 2$ prior LOTs. 1. Oaknin A, et al. Ann Oncol 2020;31(suppl 4):S1142-S1215.

\section{Plenary 2: Oral Abstract Presentations}

\section{4/\#393 DOES INTENSIVE FOLLOW-UP IMPROVE OVERALL SURVIVALIN ENDOMETRIAL CANCER PATIENTS? RESULTS FROM THE TOTEM RANDOMIZED CONTROLLED TRIAL}

${ }^{1} \mathrm{P}$ Zola*, ${ }^{2} \mathrm{G}$ Ciccone, ${ }^{3} \mathrm{R}$ Angioli, ${ }^{3} \mathrm{C}$ Terranova, ${ }^{4} \mathrm{E}$ Piovano, ${ }^{5} \mathrm{~L}$ Fuso, ${ }^{6} \mathrm{D}$ Di Cuonzo, ${ }^{1} \mathrm{E}$ Peirano, ${ }^{7} \mathrm{AM}$ Perrone, ${ }^{8} \mathrm{VD}$ Mandato, ${ }^{9} \mathrm{~L}$ Zavallone, ${ }^{10} \mathrm{~F}$ Chiudinelli, ${ }^{11} \mathrm{R}$ Berretta, ${ }^{12} \mathrm{~S}$ Loda, ${ }^{13} \mathrm{~S}$ Greggi, ${ }^{14} \mathrm{M}$ Adorni, ${ }^{15} \mathrm{E}$ Busato, ${ }^{16} \mathrm{G}$ Comerci, ${ }^{17} \mathrm{M}$ Fambrini, ${ }^{5} \mathrm{~A}$ Ferrero. ${ }^{1}$ University of Turin, Surgical Sciences, Turin, Italy; ${ }^{2}$ Città della Salute e della Scienza, University of Turin, Cancer and Epidemiology Unit, Cerms and Cpo Piemonte, Turin, Italy; ${ }^{3}$ Campus Biomedico, Gynecologic Oncology, Rome, Italy; ${ }^{4}$ Ospedale Regina Montis Regalis, Obstetrics and Gynaecology Unit, Mondovi, Italy; ${ }^{5}$ ASO Ordine Mauriziano, Obstetrics and Gynaecology Unit, Turin, Italy; ${ }^{6}$ Città della Salute e della Scienza, University of Turin, Cancer and Epidemiology Unit, Cpo Piemonte, Turin, Italy; ${ }^{7}$ University of Bologna, Gynecologic Oncology, Bologna, Italy; ${ }^{8}$ Azienda Unità Sanitaria Locale - IRCCS, Reggio Emilia, Unit of Obstetrics and Gynecology, Reggio Emilia, Italy; ${ }^{9}$ Ospedale degli Infermi, Department of Medical Oncology, Biella, Italy; ${ }^{10}$ PO Manerbio, ASST Garda, Obstetrics and Gynaecology Unit, Manerbio, Italy; ${ }^{11}$ University of Parma, Department of Medicine and Surgery, Parma, Italy; ${ }^{12}$ AO Spedali Civili, Obstetrics and Gynaecology Unit, Brescia, Italy; ${ }^{13}$ Istituto Nazionale Tumori, IRCSS, 'Fondazione G. Pascale', Department of Gynecologic Oncology, Naples, Italy; ${ }^{14}$ ASO San Gerardo de' Tintori, Obstetrics and Gynaecology Unit, Monza, Italy; ${ }^{15}$ Treviso Hospital, Obstetrics and Gynaecology Unit, Treviso, Italy; ${ }^{16}$ Santa Maria dele Croci Hospital, Obstetrics and Gynaecology Unit, Ravenna, Italy; ${ }^{17}$ University of Florence, Department of Biomedical, Experimental and Clinical Sciences, Division of Obstetrics and Gynecology, Florence, Italy

10.1136/ijgc-2021-IGCS.4 
Objectives In endometrial cancer few randomized controlled trials were conducted to assess the role of different settings of follow-up in improving overall survival. The TOTEM study (NCT00916708) was planned to compare an intensive (INT) vs minimalist (MIN) 5-year follow-up regimen in endometrial cancer patients in terms of overall survival (OS).

Methods Patients surgically treated for endometrial cancer, were stratified by center and in low (LoR) or high (HiR) risk of recurrence and then randomized to INT or MIN hospitalbased follow-up regimens. The aim of the study was to demonstrate an improvement from $75 \%$ to $80 \%$ (expected hazard ratio, $\mathrm{HR}=0.78$ ) of the 5 -year OS with the INT regimen. Secondary objectives were to compare relapse free survival (RFS) and health-related quality of life (HRQL).

Results 1884 patients were randomized in 42 centers between 2008 and 2018, and 1847 patients were available for the final analysis. After a median follow-up of 66 months, the 5-year OS was $91.3 \%, 90.6 \%$ in the INT and $91.9 \%$ in the MIN arms, respectively $(\mathrm{HR}=1.12,95 \% \mathrm{CI} \quad 0.85-1.48, \mathrm{p}=0.429)$. Comparing the INT vs MIN arms, the 5-year OS were $94.1 \%$ and $96.8 \%(\mathrm{HR}=1.48,0.92-2.37, \mathrm{p}=0.104)$ in the LoR and $85.3 \%$ and $84.7 \% \quad(\mathrm{HR}=0.96,0.68-1.36, \mathrm{p}=0.814)$ in the HiR group. The two arms did not show differences in terms of RFS and HRQL.

Conclusions Intensive follow-up in endometrial cancer treated patients did not improve OS, even in HiR patients, nor influenced health-related quality of life. Frequent routine use of imaging and laboratory exams in these patients should be discouraged.

\section{5/\#190 WHERE THERE IS SMOKE, THERE IS FIRE: UNDERSTANDING THE IMPLICATIONS OF POSITIVE SENTINEL LYMPH NODES IN ENDOMETRIAL CANCER}

\begin{abstract}
${ }^{1,2} \mathrm{G}$ Dinoi ${ }^{*},{ }^{2} \mathrm{~K}$ Ghoniem, ${ }^{3} \mathrm{Y}$ Huang, ${ }^{2} \mathrm{~V}$ Zanfagnin, ${ }^{2} \mathrm{C}$ Langstraat, ${ }^{2} \mathrm{G}$ Glaser, ${ }^{4} \mathrm{~A}$ Weaver, ${ }^{4} \mathrm{M}$ Mcgree, ${ }^{5} \mathrm{~F}$ Fanfani, ${ }^{5} \mathrm{G}$ Scambia, ${ }^{2} \mathrm{~A}$ Mariani. ${ }^{1}$ Fondazione Policlinico A. Gemelli, IRCCS, Gynaecologic Oncology, Rome, Italy; ${ }^{2}$ Mayo Clinic, Division of Gynaecologic Surgery, Department of Obstetrics and Gynaecology, Rochester, USA; ${ }^{3}$ Mayo Clinic, Division of Anatomic Pathology, Rochester, USA; ${ }^{4}$ Division of Biomedical Statistics and Informatics, Department of Health Sciences Research, Rochester, USA; ${ }^{5}$ Università Cattolica del Sacro Cuore, Department of Woman and Child Health and Public Health, Woman Health Area, Fondazione Policlinico Universitario A. Gemelli Irccs, Rome, Italy
\end{abstract}

\subsection{6/ijgc-2021-IGCS.5}

Objectives The objective of this study is to identify clinicopathologic characteristics associated with non-sentinel lymph node (SLN) metastasis and non-vaginal recurrences in patients with SLN-positive endometrial cancer (EC).

Methods Consecutive patients with surgically staged EC and at least one positive SLN were included. SLNs were ultra-staged. Positive SLNs were reviewed and patients classified according to the size of the largest SLN metastasis.

Results 103 patients (36 isolated tumor cells (ITC), 27 micrometastasis, 40 macrometastasis) were included. Multiple positive SLNs were observed in $38.8 \%$ of patients. Size of SLN metastasis (adjusted OR (aOR) 3.0 for macrometastasis vs ITC, 95\%CI 1.1-8.1), and age (aOR 1.8 per 10-year increase, $95 \%$ CI 1.1-3.0) were independent predictors of multiple positive SLNs. Extracapsular compared to intracapsular invasion of
Abstract 0005/\#190 Table 1

\begin{tabular}{|l|l|l|}
\hline Characteristic & $\begin{array}{l}\text { Adjusted } \\
\text { HR }(95 \% \mathrm{CI})\end{array}$ & $\mathrm{P}$ \\
\hline Histology & & 0.004 \\
\hline Non-endometrioid & $5.09(1.66,15.61)$ & \\
\hline Endometrioid & Reference & \\
\hline Cervical stromal invasion & & 0.002 \\
\hline No & Reference & \\
\hline Yes & $6.89(2.04,23.23)$ & \\
\hline Size of SLN metastasis & & 0.04 \\
\hline ITC/micrometastasis & Reference & \\
\hline Macrometastasis & $3.41(1.05,11.09)$ & \\
\hline
\end{tabular}

the SLN metastasis was significantly associated with multiple positive SLNs at univariate analysis $(71.4 \%$ vs. $33.7 \%$, $\mathrm{p}=0.008)$. Forty-seven percent $(18 / 38)$ of patients who underwent completion pelvic lymphadenectomy, had additional positive lymph nodes. This was associated with increased size of SLN metastasis $(0 / 8,5 / 10$, and 13/20 in ITC, micro- and macrometastasis, respectively, $\mathrm{p}=0.004)$. SLN macrometastasis (adjusted HR (aHR) 3.4, 95\%CI 1.1-11.0), non-endometrioid histology (aHR 5.7, 95\%CI 1.9-17.3), and cervical stromal invasion (aHR 9.4, 95\%CI 2.9-30.4) were independent predictors of non-vaginal recurrence (table 1).

Conclusions Size and location of SLN metastasis can predict an increased risk of multiple positive SLNs, non-SLN positive nodes, and non-vaginal recurrence in SLN positive EC patients. These factors should be assessed when considering adjuvant treatment in these high-risk patients.

\section{6/\#340 MINIMALLY INVASIVE SURGERY IN ADVANCED ENDOMETRIAL CARCINOMA IS ASSOCIATED WITH AN INCREASED RISK FOR LOCAL RECURRENCE}

${ }^{1} \mathrm{~L}$ Kogan*, ${ }^{2} \mathrm{G}$ Levin, ${ }^{3} \mathrm{~L}$ Helpman, ${ }^{4} \mathrm{R}$ Eitan, ${ }^{5} \mathrm{Z}$ Vaknin, ${ }^{6} \mathrm{O}$ Lavie, ${ }^{7} \mathrm{~A}$ Ben Arie, ${ }^{8} \mathrm{~A}$ Amit, ${ }^{9} \mathrm{~T}$ Levy, ${ }^{10} \mathrm{~A}$ Namazov, ${ }^{11}$ I Ben Shachar, ${ }^{12}$ I Atlas, ${ }^{13}$ I Bruchim, ${ }^{1} \mathrm{~B}$ Brandt, ${ }^{14} \mathrm{O}$ Gemer. ${ }^{1}$ Hadassah, Gynecologic Oncology, Jerusalem, Israel; ${ }^{2}$ hadassah medical center, Gynecologic Oncology, jerusalem, Israel; ${ }^{3}$ Cheba medical center, Gynecologic Oncology, Ramat Gan, Israel; ${ }^{4}$ Rabin Medical Center, Gynecology, Petah Tikva, Israel; ${ }^{5}$ Assaf Haroffe Medical Center, Sackler School of Medicine, Gynecology, Zrifin, Israel; ${ }^{6}$ Carmel Medical Center, Obstetrics and Gynecology, Haifa, Israel; 72 2. Kaplan Medical Center, Hebrew University, Gynecology, Rehovot, Israel; ${ }^{8}$ Rambam, Gymecologic Oncology, Haifa, Israel; ${ }^{9} 8$. Wolfson Medical Center, Holon, Sackler Faculty of Medicine, Tel Aviv University, Gynecology, Tel Aviv, Israel; ${ }^{10}$ Ahmet, Gynecology, Ashkelon, Israel; ${ }^{11}$ Zlv, Gynecologic Oncology, Zefat, Israel; ${ }^{12}$ Poriah, Gynecologic Oncology, Tiberia, Israel; ${ }^{13}$ Hillel Yafe, Gynecology, Hadera, Israel; ${ }^{14}$ Barzilai Medical Center, Gynecology, Ashkelon, Israel

\subsection{6/ijgc-2021-IGCS.6}

Objectives To compare oncological outcomes of women with stage II -IIIc endometrial cancer (EC) who underwent minimally invasive surgery (MIS) versus laparotomy.

Methods A retrospective cohort study in an academic multicenter setting. Consecutive women with EC treated at 11 Israeli institutions between 2002 and 2017 were recorded in an assimilated database with a median follow-up of 52 months (range 12-120 months). Women with stage II -IIIc were stratified into groups by intentional route of surgery; MIS vs. laparotomy. Clinical, pathological and outcome data were compared. 